\title{
O USO DA LITERATURA INFANTIL NO ENSINO DE GEOGRAFIA NOS ANOS INICIAIS
}

USE IN CHILDREN'S LITERATURE TEACHING OF GEOGRAPHY IN THE EARLY YEARS

\author{
Rosa Elisabete Militz Wypyczynski Martins \\ Universidade do Estado de Santa Catarina (UDESC), Florianópolis, SC, Brasil, rosa.martins@udesc.br
}

\section{RESUMO}

Propõe-se, por meio deste artigo, uma discussão sobre o uso da literatura infantil como estratégia ao desenvolvimento de diferentes atividades pedagógicas para ensinar Geografia. Apresenta-se um projeto desenvolvido numa turma de Pedagogia na disciplina de Fundamentos Metodológicos do Ensino de Geografia, destacando-se como este tipo de literatura pode ser utilizado estrategicamente na metodologia de aula da educação infantil e nos anos iniciais, com o propósito de contribuir para a construção da aprendizagem da ciência geográfica. É realçada a importância da alfabetização e da alfabetização Geográfica nos anos iniciais e na educação infantil. Discute-se a importância de se aprender Geografia nos anos iniciais do ensino fundamental, a qual, muitas vezes, é ensinada de forma desconexa, independentemente da vida dos alunos, não utilizando, em grande parte, o aparato conceitual dessa ciência. Entendemos que o papel da Geografia nos anos iniciais deve ser o de desenvolver conhecimentos que sejam significativos para a criança conhecer o espaço em que vive e fornecer subsídios à apreensão da paisagem, ampliando a noção de espaço.

Palavras-chave: Geografia; literatura infantil; anos iniciais; alfabetização.

\section{ABSTRACT}

This paper proposes a discussion on the use of children's literature as a strategy for the development of different educational activities to teach Geography. Presents a project developed a class of pedagogy in the discipline of Methodological Foundations of Teaching Geography which sought to highlight how this kind of literature can be used as a methodological strategy in the classroom of kindergarten and in the early years, with the aim of contributing to construction of learning of geographical science. Highlights the importance of literacy and Geographic literacy in the early years and early childhood education. Discusses the importance of learning Geography in the early years of primary school, which is often taught in a disconnected way of life of the students and does not use largely the conceptual apparatus that science. We understand that the role of geography in the early years should be to develop skills that are meaningful to the child know the space you live in and provide support for apprehension of landscape and expand the notion of space.

Keywords: Geography; children's literature; the early years; literacy

Artigo recebido para publicação em julho de 2014

Artigo aceito para publicação em agosto de 2015

\section{INTRODUÇÃO}

O momento histórico atual exige que se repense a educação/escola para que as práticas pedagógicas possam ser efetivadas, a fim de que contribuam na transformação da realidade e melhoria da qualidade do ensino. Pensando, nesse sentido, é necessário que a escola/professor defina objetivos e propostas de uma ação educativa coletiva que ofereça o preparo do educando da melhor forma possível, para $o$ enfrentamento do seu cotidiano. A escola e os modelos tradicionais de ensino estão sendo questionados, 
pois não dão conta de uma realidade em constante transformação. Para Mello, "a principal questão reside no fato de haver uma significativa distância entre o perfil da escola e do professor necessário e o perfil existente para enfrentar as demandas desse novo cenário" (2004, p. 99).

Cabe, assim, analisar a importância do período de alfabetização, etapa das aprendizagens essenciais para o domínio dos códigos básicos da sociedade e indispensáveis ao exercício da cidadania. A avaliação criteriosa dos referenciais teórico-metodológicos na sistematização do conhecimento é essencial ao bom nível do processo ensino-aprendizagem.

As relações com o contexto histórico e social são fundamentais para que o ensino seja eficaz, atraente, curioso e capaz de instrumentalizar os educandos à compreensão do mundo atual. É preciso romper com uma visão fragmentada, linear, das ações educativas e promover práticas que favoreçam a formação da cidadania. Faz-se necessário o entendimento de que:

\footnotetext{
Ensinar já não significa transferir pacotes sucateados, nem mesmo significa meramente repassar o saber. Seu conteúdo correto é motivar o processo emancipatório com base em saber crítico, criativo, atualizado, competente. Trata-se, não de cercear, temer, controlar a competência de quem aprende, mas de abrir a chance na dimensão maior possível. Não interessa o discípulo, mas o novo mestre. Entre o professor e o aluno não se estabelece apenas hierarquização verticalizada, que divide papéis pela forma do autoritarismo, mas, sobretudo, confronto dialético. Este se alimenta da realidade histórica formada por entidades concretas que se relacionam de modo autônomo, como sujeitos sociais plenos. (DEMO, 1993, p. 153).
}

A compreensão do conceito de alfabetização tem passado, ao longo dos anos, por várias modificações e se efetiva de maneira bastante diversificada entre os educadores. Há um leque de estudos a respeito da alfabetização $^{1}$ que procura dar conta da compreensão do processo que a criança percorre ao se apropriar da linguagem escrita.

Muitos pesquisadores de diferentes campos ${ }^{2}$ tomaram como temática e objeto de estudo a questão da leitura e da escrita, seu processo de ensino e aprendizagem, buscando superar concepções "tradicionais" que não dão conta das reais necessidades das crianças. A alfabetização passa a ser

${ }^{1}$ Podemos citar trabalhos de: FERREIRO, Emilia (1995); FERREIRO, Emilia; TEBEROSKY (1985); KATO, Mary; MOREIRA, Nadja; TARALLO, Fernando (1997); SMOLKA, Ana Luiza B. (1999).

${ }^{2}$ Podemos citar trabalhos de: HICKMANN, (2010); LERNER, Delia (2002); STRAFORINI, Rafael (2004) 
compreendida como um processo contínuo e evolutivo, requerendo a integração das práticas sociais com o cotidiano da vida da criança. Para Braggio (1992, p. 40):

\footnotetext{
Alfabetização é um fenômeno social complexo que é determinado pelo papel da língua escrita no funcionamento de uma comunidade. Alfabetização, então, é muito mais do que a habilidade técnica ou um conjunto de comportamentos isolados que podem ser considerados independentemente do contexto social no qual ocorre. (...) É um complexo de habilidades funcionais entre os quais a habilidade para decodificar é somente o primeiro passo.
}

Já, para Val (2006, p. 66),

\begin{abstract}
alfabetização pode ser definida como processo específico e indispensável de apropriação do sistema de escrita, a conquista dos princípios alfabético e ortográfico que possibilitem ao aluno ler e escrever com autonomia. Noutras palavras, alfabetização diz respeito à compreensão e ao domínio do chamado "código" escrito, que se organiza em torno de relações entre a pauta sonora da fala e as letras (e outras convenções) usadas para representá-la, a pauta, na escrita.
\end{abstract}

A compreensão de que a alfabetização é um processo amplo e permanente contribui para o desenvolvimento de práticas comprometidas com a dimensão política e social da aprendizagem na formação de sujeitos autônomos. Segundo Lerner (2002, P. 27), temos o compromisso de "formar seres humanos críticos, capazes de ler entrelinhas e de assumir uma posição própria, frente à mantida, explícita ou implicitamente, pelos autores dos textos com os quais interagem".

Entendendo a alfabetização para além de um simples domínio das técnicas de ler e escrever, compreendendo capacidades e conhecimentos múltiplos, respaldamo-nos em Frago (1993) que destaca que uma concepção mais ampla de alfabetização deveria contemplar também a capacidade para decifrar/decodificar outros signos diferentes dos alfabéticos A leitura do mundo, das paisagens, dos instrumentos de comunicação, da linguagem escrita, ocorrida nos mais variados contextos sociais, também faz parte do processo de alfabetização e precisa ser compreendida e representada. Nesse contexto de imagens, cada vez mais heterogêneas, a alfabetização geográfica é importante e precisa ser trabalhada nas séries iniciais.

Segundo Castrogiovanni (2000, p. 11), a alfabetização geográfica ou espacial: 
Deve ser entendida (como) a construção de noções básicas de localização, organização, representação e compreensão da estrutura do espaço, elaboradas dinamicamente pelas sociedades. (Aqui), a representação dos segmentos espaciais é fundamental no processo de descentralização do aluno facilitando a leitura do todo espacial.

Refletir sobre a construção do conhecimento geográfico nas séries iniciais remete à compreensão de que é preciso superar a concepção de que alfabetização é aquisição da leitura e da escrita. Isso pressupõe que o educador rompa com o "tradicional" e procure repensar sua prática e seus referenciais, no sentido de possibilitar aos educandos o acesso a um conhecimento que é fundamental para a compreensão do mundo que ele vive. Segundo Callai (2005, p. 232), é preciso buscar caminhos para se ensinar Geografia nos anos iniciais, e essa busca deve estar "centrada no pressuposto básico de que, para além da leitura da palavra, é fundamental que a criança consiga fazer a leitura do mundo.”

Também, porque comungo das ideias de Almeida (1999, p. 83), a qual afirma que a finalidade da geografia é "munir os alunos de conhecimentos que lhes permitam agir de modo mais lúcido ao tratar das questões do espaço em diferentes níveis. O ensino da geografia tem, portanto, papel decisivo na formação da cidadania." Para romper com essa prática e promover a construção de um saber geográfico sólido nos anos iniciais, o professor precisa ter clareza teórica e metodológica para poder “contextualizar os seus saberes, os dos seus alunos e os de todo o mundo à sua volta" (CALLAI, 2005, p. 231). Isso envolve o domínio de conceitos básicos da geografia, que são fundamentais para o desenvolvimento das aulas. A carência de uma formação específica na área da geografia pode contribuir como fator inibidor de uma alfabetização geográfica.

Nesse sentido, surge a necessidade de questionar se os referenciais que os professores trabalham nos anos iniciais estão contribuindo para orientá-los na aplicação dos conhecimentos geográficos nas atividades de sala de aula. Trabalhar o conhecimento geográfico nos anos iniciais, numa abordagem que se reduz à execução das tarefas de decodificação mecânica de símbolos, mapas e representações, contribui para que a criança não consiga estabelecer a relação entre o conhecimento construído na escola e as informações que recebe no seu cotidiano. De acordo com Castrogiovanni (2000, p. 13), isso colabora para o distanciamento entre a escola e o mundo da vida. 
Existe ainda pouca aproximação da escola com a vida, com o cotidiano dos alunos. A escola não se manifesta atraente frente ao mundo contemporâneo, pois não dá conta de explicar e textualizar as novas leituras de vida. A vida fora da escola é cheia de mistérios, emoções, desejos e fantasias, como tendem a ser as ciências. A escola parece homogênea, transparente e sem brilho no que se refere a tais características. É urgente teorizar a vida, para que o aluno possa compreendê-la e representá-la melhor e, portanto, viver em busca de seus interesses.

É importante que se tenha presente que a alfabetização geográfica se constitui numa etapa importante de ensino e aprendizagem nos anos iniciais. O preparo do aluno para a leitura e representação do espaço, apropriação de conceitos importantes a sua vida, entendimento da dinâmica da sociedade lhe possibilitam a compreensão do mundo em que vive. Nesse sentido, Callai (2005, p. 233) afirma que, quando a criança chega à escola, "ela vai aprender a ler as palavras, mas qual o significado destas, se não forem para compreender mais e melhor o próprio mundo."

Entendemos que o papel da Geografia nos anos iniciais deve ser o de desenvolver conhecimentos que sejam significativos para a criança conhecer o espaço em que vive e fornecer subsídios à apreensão da paisagem e ampliação da noção de espaço. Para dar conta deste objetivo, faz-se necessário que o ensino da Geografia esteja vinculado à realidade local dos alunos, à construção de valores e ao pertencimento a este lugar. De acordo com Straforini (2004, p. 18):

E, acima de tudo, considero que estudar o lugar para compreender o mundo significa para o aluno a possibilidade de trilhar no caminho de construir a sua identidade e reconhecer o seu pertencimento. Faltamnos muito esses valores de identidade e pertencimento num mundo que se pretende homogêneo, mas que é contraditório e diverso tanto nas relações entre os homens, e destes com a natureza, assim como no espaço que estamos construindo no cotidiano de nossas vidas.

Para Callai (2005), neste nível de ensino, o da Geografia tem de dar conta de ler o mundo da vida dos alunos, considerando a realidade concreta e a história do espaço vivido.

Compreender o lugar em que se vive encaminha-nos a conhecer a história do lugar e, assim, a procurar entender o que ali acontece. Nenhum lugar é neutro, pelo contrário, os lugares são repletos de historia e situam-se concretamente em um tempo e em um espaço fisicamente delimitado. As pessoas que vivem em um lugar estão historicamente situadas e contextualizadas no mundo. Assim, o lugar não pode ser considerado/entendido isoladamente. O espaço em que vivemos é o resultado da história de nossas vidas. Ao mesmo tempo em que ele é o palco onde se sucedem os fenômenos, ele é também ator/autor, uma vez que oferece condições, põe limites, cria possibilidades. (CALLAI, 2005, p. 236.) 
A ciência geográfica está presente no currículo dos anos iniciais (primeiro ciclo) e tem por objetivos, nesta modalidade de ensino, segundo os PCNS:

\footnotetext{
- Reconhecer, na paisagem local e no lugar em que se encontram as diferentes manifestações da natureza e a apropriação e transformação dela pela ação de sua coletividade, de seu grupo social;

- Conhecer e comparar a presença da natureza, expressa na paisagem local, com as manifestações da natureza presentes em outras paisagens;

- Reconhecer semelhanças e diferenças nos modos que diferentes grupos sociais se apropriam da natureza e

a transformam, identificando suas determinações nas relações de trabalho, nos hábitos cotidianos, nas formas de se expressar e no lazer:

- Conhecer e começar a utilizar fontes de informação escritas e imagéticas utilizando, para tanto, alguns procedimentos básicos;

- Saber utilizar a observação e a descrição na leitura direta ou indireta da paisagem, sobretudo por meio de ilustrações e da linguagem oral;

- Reconhecer, no seu cotidiano, os referenciais espaciais de localização, orientação e distância de modo a deslocar-se com autonomia e representar os lugares onde vivem e se relacionam;

- Reconhecer a importância de uma atitude responsável de cuidado com o meio em que vivem, evitando o desperdício e percebendo os cuidados que se deve ter na preservação e na manutenção da natureza. ( BRASIL, 1997, p. 130-131).
}

Para dar conta destes objetivos, são muitas as possibilidades que podem ser trabalhadas pelo professor em sala de aula, a fim de que os alunos possam apropriar-se dos conceitos da educação geográfica na sua aprendizagem. Uma dela é o uso da literatura infantil como uma estratégia para o desenvolvimento de diferentes atividades pedagógicas.

Como sabemos, a literatura infantil é importante nesta faixa etária em que as crianças se encontram nos anos iniciais do ensino fundamental, pois despertam o imaginário da criança. É uma fase fundamental para estimular o gosto pela leitura, para explorar a oralidade, enriquecer o vocabulário, provocar o imaginário e a fantasia, fazendo com que elas possam viajar pelo mundo da imaginação. São narrativas que contribuem ao desenvolvimento intelectual e emocional das crianças e servem como experiências simbólicas de como enfrentar as questões reais do dia a dia, como lidar com o bem e o mal e como vivenciar vitórias e derrotas.

Além disso, a literatura infantil tem um papel importante no trabalho pedagógico do professor em sala de aula, servindo de recurso no desenvolvimento da linguagem oral, do lúdico e para despertar o gosto pela leitura. Como um recurso metodológico, a literatura infantil serve para trabalhar diversos conceitos e valores importantes à formação e ao convívio social das crianças. Serve como base para 
diferentes projetos pedagógicos que podem envolver diferentes áreas do currículo escolar, através de atividades de aprendizagem e brincadeiras. A contagem das histórias infantis cria um ambiente propício para exercitar a imaginação, gerando um ambiente em que os personagens, o ambiente narrado nas histórias, os objetos, os sons se aproximam da realidade das crianças e servem para que elas possam relacioná-los com seu cotidiano, mostrando como lidar em situações reais do dia a dia, tais como preservação ambiental, cuidado com os animais, respeito aos colegas, alimentação saudável, etc.

O inicio da escolarização é um período em que a criança precisa se ambientar no novo espaço, que é diferente do familiar. Ela passa a ficar em contato com um mundo novo e é preciso lhe oferecer o contato com inúmeras possibilidades de atividades lúdicas, práticas e afetivas que contribuam para o seu desenvolvimento. As oportunidades oferecidas permitirão um contato maior com experiências positivas para sua aprendizagem. De acordo com Hickmann (2002, p. 9-10):

\footnotetext{
[...] uma articulação entre o ambiente físico e social e o processo de construção das múltiplas identidades que nos constituem ao longo da trajetória de vida (pessoal, social, cultural). Significa refletir sobre a possibilidade de se proporcionar às crianças oportunidades de interação com outros indivíduos, que as levem à independência, à cooperação e à colaboração voluntária e não à competitividade, concorrência e individualismo, ao perceberem que os outros, com os quais convivem, também têm sentimentos, opiniões e direitos.
}

Ensinar geografia envolve muito mais que solicitar aos alunos/as que façam cópias de mapas, construam maquetes ou o roteiro de casa à escola. Para efetivar uma aprendizagem de Geografia é fundamental que as aulas tenham sentido com atividades interessantes e lúdicas, que mobilize o interesse dos alunos.

\section{TROCANDO EXPERIÊNCIAS}

Com o objetivo de estimular a aprendizagem da Geografia nos anos iniciais, foi organizado projeto com o uso da literatura infantil na disciplina de Fundamentos Metodológicos do Ensino de Geografia em uma turma do curso de Pedagogia, na qual foi destacado que este tipo de literatura serve de estratégia metodológica na sala de aula da educação infantil e nos anos iniciais, com o propósito de contribuir para a construção da aprendizagem da ciência geográfica. A intenção com este projeto era a de 
mostrar as possibilidades de se trabalhar com Geografia, através do uso das histórias infantis que são muito utilizadas neste nível de ensino. Muitas vezes, os professores não trabalham com Geografia, porque desconhecem o potencial dos materiais didáticos disponíveis, relacionados aos conceitos desta ciência.

Inicialmente, foi distribuído às alunas um texto da Roseli Inês Hickmenn - "Ciências sociais no contexto escolar: para além do espaço e do tempo ${ }^{3}$, no qual a autora busca pontuar alguns princípios, sugerindo algumas práticas que podem ser utilizadas nas aulas de história e geografia na educação infantil e anos iniciais; problematiza a questão do uso das "famosas datas comemorativas" e discute a inclusão de uma perspectiva de análise e reflexão interdisciplinar à área das ciências sociais; propõe uma articulação entre o ambiente físico e social para o processo de construção da identidade das crianças neste período escolar. A autora sugere algumas histórias infantis e algumas músicas que podem ser trabalhadas em sala de aula para dar conta de temáticas como: direitos humanos, racismo, cidadania, inclusão, racismo, amizade, convivência, etc.

Após a leitura e discussão deste texto, foram organizados grupos na sala de aula em que cada um teria de escolher um livro de história infantil, para criar uma forma de trabalhar a história como apoio didático na organização de um projeto, com aulas a serem desenvolvidas numa turma de alunos/as de educação infantil ou de anos iniciais. O projeto detinha atividades interdisciplinares e de ensino de Geografia. O primeiro passo foi fazer a leitura da história e verificar quais as possibilidades de explorar o tema central e como expor aos alunos, de forma lúdica, com o intuito de lhes chamar a atenção.

É histórico o papel coadjuvante da Geografia nos anos iniciais, pois muitos professores e os próprios alunos/as do curso de Pedagogia relatam que têm dificuldade ou não sabem como trabalhar os conhecimentos desta ciência em sala de aula. Quando é trabalhada, é muito ligada ao uso do livro didático ou são utilizadas metodologias de ensino que perpetuam uma Geografia ligada a propostas

\footnotetext{
${ }^{3}$ HICKMANN (2010).
} 
tradicionais que valorizam as memorizações, em oposição à reflexão e ao uso conceitual como forma de levar à compreensão do espaço vivenciado pelos educandos.

Callai (2005) reforça a necessidade de se refletir sobre o ensino de Geografia nos anos iniciais no processo de formação inicial dos professores que atuam com este nível de ensino. Destaca que os professores têm de estar munidos de referenciais teóricos metodológicos que os auxiliem no momento de pensar nos objetivos e no planejamento das atividades do ensino de Geografia; isso permitirá a construção de métodos de análise do espaço geográfico, a fim de que os alunos se reconheçam no interior deste espaço.

\footnotetext{
Para romper com a prática tradicional da sala de aula, não adianta apenas a vontade do professor. É preciso que haja concepções teórico-metodológicas capazes de permitir o reconhecimento do saber do outro, a capacidade de ler o mundo da vida e reconhecer a sua dinamicidade, superando o que está posto como verdade absoluta. É preciso trabalhar com a possibilidade de encontrar formas de compreender o mundo, produzindo um conhecimento que é legítimo. (CALLAI, 2005, p. 231)
}

Como professora de Metodologia do Ensino de Geografia em cursos de Pedagogia e também nos de Geografia, preocupa-me sempre o que irão ensinar de Geografia, nas escolas, os professores que atuarão nos anos iniciais e, também, nos anos finais do ensino fundamental e no ensino médio. Como neste texto estamos falando dos anos iniciais, centrei minha reflexão neste nível de ensino.

Sempre que inicio as aulas de Metodologia do Ensino de Geografia numa turma de Pedagogia, questiono sobre os conhecimentos geográficos que a turma possui. Invariavelmente, eles respondem que lembram pouco das suas aulas de geografia e os que lembram relatam sobre atividades relacionadas à pintura de mapas, nome de rios, cidades, capitais e atividades no livro didático, caracterizadas pela enumeração de dados geográficos de espaços fragmentados. São falas que revelam atividades desconectadas de um contexto social ou de uma geografia vivida por todos nós. Diante disso, questiono sobre o que eles acreditam ser importante ensinar em Geografia nos anos iniciais. Alguns revelam que têm dificuldade em trabalhar com Geografia, pois não sabem como fazer ou não se sentem seguros em abordar alguns conceitos desta ciência. 
Procuro esclarecer que ensinar Geografia envolve mais que trabalhar com o livro didático, pintar mapas, fazer planta da sala de aula, fazer roteiros de casa para a escola que, normalmente, são atividades que estamos acostumados a ver em listagem de conteúdos dos anos iniciais. Ensinar Geografia pressupõe entender que o espaço geográfico é algo dinâmico e está em constante transformação e, como tal, impõe uma análise que privilegie o movimento, isto é, discutir o espaço como resultado de um processo histórico que envolve o passado, o presente e o futuro.

O primeiro grupo escolheu a história infantil "Abrapracabra: uma viagem mágica pelo mundo da literatura ${ }^{4} "$. O livro conta a história de uma cabra que encontra uma lâmpada encantada e dela sai um gênio que diz: "Pense numa palavra mágica, mas cuidado ao falar. O desejo imaginado, ela irá realizar”. A cabra então, fala: “Abrapracabra!”. Do nada, surge uma porta. A partir de então, a cabra inicia uma viagem por várias partes do mundo. O primeiro lugar, ao qual a porta a leva, é o Polo Norte, onde ela encontra um grande urso-polar. Com medo de morrer congelada, a cabra repete a palavra mágica e um novo portal se abre. Ela cai então no Egito, com o urso-polar ao seu lado. Lá, conhecem um camelo. Assustada com a possibilidade de virar comida, a cabra fala "abrapracabra!" e um novo portal se abre e ela continua sua viagem.

O grupo organizou um projeto para ser desenvolvido no segundo ano dos anos iniciais com duração de uma semana. Após a leitura da história para os alunos, foram feitas diversas atividades, explorando a história entre elas podemos destacar uma chamada "conhecendo diferentes lugares". O objetivo era o de buscar os diferentes lugares em que cada personagem morava, destacando as suas características e localização no mapa. Com o mapa exposto em sala de aula, foi proposto aos alunos escolherem um lugar para fazer uma viagem imaginária. Cada um deveria eleger um meio de transporte para viajar, criando um roteiro para tal viagem. Deveriam verificar por quantos países passariam até chegar ao lugar escolhido, quais as características da paisagem do lugar e como os habitantes de lá viviam, a alimentação e os hábitos. Em dupla, deveriam fazer um cartaz com colagem, desenhos e pequenos textos para mostrar aos colegas qual o lugar escolhido para tal viagem. Esta atividade foi importante

${ }^{4}$ VILELA, Fernando. Abrapracabra. Coleção na Mochila. São Paulo: Editora Brinque-book, 2013. 
para os alunos perceber os diferentes meios de transportes, como vivem os animais em diferentes regiões do mundo, a localização de vários países, regiões e suas características físicas, humanas e sociais.

O segundo grupo escolheu a história infantil "As Três Porquinhas", fazendo uma adaptação do clássico da literatura infantil "os três porquinhos". O projeto "interdisciplinaridade com a história adaptada às três porquinhas", foi planejado para ser desenvolvido numa turma do quarto ano dos anos iniciais, utilizando de atividades interdisciplinares que buscassem unir as fronteiras, até então, solidamente construídas entre os diferentes componentes curriculares do currículo escolar.

Após a leitura da história para os alunos/as, foi feita uma rodada de questões sobre a história, para que todos pudessem opinar, explorar, participando do tema. Num segundo momento, foi proposta uma atividade de pesquisa em jornais e revistas sobre diferentes tipos de moradias, a fim de que todos percebessem como as pessoas vivem em diferentes espaços da cidade ou de um espaço rural; como são as casas das zonas centrais da cidade e das zonas mais periféricas; tipos de construção e materiais utilizados. Cada grupo teve de fazer um painel com recortes dos tipos de moradias pesquisados. Num terceiro momento do projeto, propôs-se um trabalho de campo na cidade, com a intenção de que os alunos/as pudessem observar as moradias e também perceber como as pessoas vivem no próprio local onde moram. Neste mesmo dia da saída de campo, os alunos foram até uma loja de materiais de construção para fazer uma pesquisa sobre o preço dos materiais utilizados na construção de uma casa. Esta pesquisa foi utilizada numa aula de matemática para trabalhar com questões que envolvem problemas matemáticos.

O terceiro grupo fez a opção pela história infantil "O Mundinho 5 ". A história conta que era uma vez um mundinho, com suas plantas, animais e rios. Um dia, os homenzinhos foram viver nele. Mas esqueceram de preservar o espaço onde viviam. A autora destaca a importância da água para a vida e de sua preservação e convida o leitor a salvar o mundinho azul. O objetivo do grupo com a escolha

\footnotetext{
${ }^{5}$ BELlinghaUSEN, Ingrid Biesemeyer. O Mundinho. São Paulo: Editora Del Difusao Cultural, 2008.
} 
desta história foi o de despertar o respeito ao meio ambiente, através de atividades pedagógicas que proporcionem o desenvolvimento de competências e ampliem o conhecimento da leitura, da escrita, da oralidade e de Geografia.

Com o tema "a preservação ambiental do bairro", o grupo organizou um projeto com várias atividades para explorar a história. Após a leitura e apresentação de imagens que mostraram a degradação do meio ambiente, foi feita uma rodada de conversa sobre a história e sobre a importância de preservar o planeta. Os alunos montaram um painel com imagens e desenhos que mostravam a importância da preservação ambiental e sobre os principais problemas ambientais que temos no mundo atual.

$\mathrm{Na}$ aula seguinte, foram trabalhados, em sala, os conceitos de cidade, bairro, estado e país, explorando o Google Earth e organizando uma saída de campo pelo bairro da escola, a fim de conhecer a realidade ambiental encontrada. Fizeram-se fotos e a coleta de material para trabalhar em sala de aula, na qual os alunos construíram um painel com as imagens e desenhos do que foi encontrado no bairro. Continuando com o projeto, foi realizada uma pesquisa sobre o tempo de degradação de cada poluente encontrado na saída de campo: a garrafa pet, sacola plástica, chiclete, como plástico, bateria de celular, lata de refrigerante, moeda, entre outros.

O quarto grupo escolheu a história infantil "A Cesta da Dona Maricota", em que é narrada a volta de Dona Maricota da feira onde comprou diversos legumes e frutas e, ao chegar a casa, preparou diversos alimentos.

O grupo organizou um projeto chamado "aprenda a comer bem para viver melhor", para desenvolver as atividades em sala de aula com uma turma do terceiro ano dos anos iniciais; justificou-se a escolha por este tema, em razão de que muitas crianças estão acima do peso e são seletivas na sua alimentação. Então, o objetivo do grupo foi o de conscientizar sobre a importância da alimentação saudável, por meio da literatura e de atividades prazerosas em sala de aula. A base dos hábitos alimentares é

${ }^{6}$ BELINKY, T. A cesta de Dona Maricota. São Paulo: Editora Paulinas, 2007. 
formada na infância e necessita de um processo educativo, e a escola serve como espaço de extrema importância na formação de um padrão alimentar saudável.

A proposta do grupo ao contar a história da "cesta da Dona Maricota" foi a de utilizar o avental de histórias ${ }^{7}$. Após a apresentação, uma roda de conversa sobre alimentação saudável, em que cada aluno deveria relatar como era sua alimentação no seu dia a dia. Na sequência, foram propostas as seguintes atividades: visita a uma feira para comprar frutas com a intenção de organizar uma salada de frutas. Com os preços pagos pelas frutas foram organizadas atividades na aula de matemática; também foi proposta uma pesquisa sobre as propriedades nutricionais das frutas e organização de um painel com os dados obtidos.

O quinto grupo optou pela história infantil "Caraoquê, o Caracol" ", na qual é contada a história de Caraoquê - um caracol que vivia muito triste, carregando sempre a sua casinha. Ele queria ter asas como a borboleta azul, para voar de flor em flor. Caraoquê também queria cantar como o canarinho amarelo, mas não conseguia; ele já estava cansado de imitar a borboleta azul e o canarinho amarelo. O Doutor Sapo conversou com o Caraoquê e lhe explicou que Deus havia criado cada animal de uma maneira, e todos deveriam ficar felizes como são. Caraoquê pensou... pensou... e viu que o Doutor Sapo tinha razão. Caraoquê se tornou o bichinho mais feliz daquele bosque.

O Grupo organizou um projeto chamado "conhecendo a diversidade dos animais domésticos e selvagens" para ser desenvolvido em uma turma de educação infantil. A escolha do tema do projeto teve, como propósito, o despertar do interesse natural das crianças em relação aos animais; a identificação dos difrentes tipos de animais domésticos e selvagens; a alimentação e o seu habitat natural, estimulando a solidariedade e o respeito aos animais.

As atividades para explorar a história com as crianças foram as seguintes: a primeira proposta foi a de fazer uma roda para ouvir a contação da história e explorar oralmente a temática proposta pela autora,

\footnotetext{
${ }^{7} \mathrm{O}$ avental para contação da história é um recurso metodológico que conta com um avental que é todo de feltro, o cenário e os personagens são de E.V.A. O cenário é fixo no avental, já os personagens são móveis, colados com velcro o que permite ir narrando a história e encaixando os personagens.

${ }^{8}$ PINTO, Gerusa Rodrigues. Caraoquê, o caracol. Belo Horizonte, MG: Editora Fapi, 2005.
} 
mostrando que os animais são diferentes um dos outros e que todos são muito importantes para 0 equilíbrio da natureza. Alguns vivem perto de nós e outros não. Todos têm de ser cuidados e respeitados. Após, cada criança recebeu uma máscara com a imagem de um animal, sobre o qual deveriam falar o que sabiam, ou seja, do animal representado na máscara; como vive, como se alimenta, se é selvagem ou doméstico e onde vive. A segunda atividade foi a de mostrar, através de fotos e figuras, a diferença entre animais selvagens e domésticos, como também o habitat de cada animal. Após a identificação dos animais, um painel foi montado, separando os animais domésticos dos selvagens. A terceira atividade foi a de entregar para as crianças uma folha com pegadas de animais para ver se elas as identificavam. Numa caixa havia a figura correspondente de cada animal com sua pegada na folha entregue para as crianças, que deveriam relacionar o animal com a respectiva pegada.

Com o objetivo de que todos/as os alunos/as conhecessem o projeto dos colegas, organizamos um seminário no mês de outubro de 2013 para socializar todos os projetos propostos pelos cinco grupos. Acreditamos ser fundamental este momento de socialização para troca de ideias e possibilitar a todos/as tivessem o acesso aos temas e atividades propostas nos projetos de cada grupo.

\section{CONSIDERAÇÕES FINAIS}

Procura-se, neste artigo, apresentar algumas reflexões sobre o uso da literatura no ensino da disciplina de Geografia nos anos iniciais e na educação infantil, destacando a importância da alfabetização geográfica nesta etapa da escolarização. Acredita-se que a alfabetização vai além da aquisição da leitura e da escrita, e que a Geografia, como ciência, possui um grande papel na formação das crianças. O ensino dessa disciplina contribui para a inserção e a compreensão do indivíduo no espaço geográfico e às relações que nele acontecem, havendo um instrumental conceitual que possibilita aos alunos fazer a leitura do mundo, que é fundamental ao exercício da cidadania.

O grande desafio é propor alternativas metodológicas que contribuam para que os alunos possam apropriar-se de conceitos geográficos importantes na compreensão do seu espaço vivido, para que percebam que ele não é estático e, sim, que está em constante transformação. De acordo com Callai 
(2005, p. 288-289), "ler o mundo da vida, ler o espaço e compreender que as paisagens que podemos ver são resultado da vida em sociedade, dos homens na busca da sua sobrevivência e da satisfação das suas necessidades".

Através da socialização de um projeto sobre o uso da literatura infantil no ensino da Geografia nos anos iniciais e na educação infantil, desenvolvido em uma disciplina de Fundamentos Metodológicos do Ensino de Geografia numa turma de Pedagogia, houve o destaque a este tipo de literatura, a qual pode ser utilizada estrategicamente na metodologia da educação; procuramos mostrar, com esta experiência, a possibilidade de despertar a curiosidade e o interesse dos alunos pelo jeito diferente de estudar Geografia.

O universo da Literatura Infantil é muito amplo e rico e há inúmeras obras de autores brasileiros e estrangeiros disponíveis a serem aproveitados em sala de aula, com um potencial enorme para trabalhar diferentes conceitos da Geografia, despertando o imaginário e a curiosidade das crianças; facilitando a interlocução e a aprendizagem do significado de diferentes espaços, paisagens, tempos, lugares, culturas, etc.; ampliando os conhecimentos a respeito da realidade, não sendo limitados aos bairros, cidades, estados ou países, ou ao presente, passado e futuro.

Acreditamos que os professores podem se valer destes materiais didáticos e recursos pedagógicos, como auxílio no desenvolvimento das aulas de Geografia nos anos iniciais, possibilitando aos alunos maior compreensão dos conhecimentos desta ciência, pois, segundo Callai (2005), a Geografia, nos anos iniciais da escolarização pode e, muito, contribuir com o aprendizado da alfabetização, uma vez que encaminha para aprender a ler o mundo.

\section{REFERÊNCIAS}

ALMEIDA, R. D. Ensinar geografia para quem vive num outro mundo. In: ENCONTRO NACIONAL DE PRÁTICA DE ENSINO EM GEOGRAFIA. № 5. Anais: Belo Horizonte, PUC/MG, 1999.

BRAGGIO, Silva L. Bigonjal. Leitura e alfabetização: da concepção mecanicista à sócio- psicolinguística. Porto Alegre: Artes Médicas, 1992. 
BRASIL, Ministério de Educação e Cultura, Secretaria de Educação Fundamental. Parâmetros Curriculares Nacionais: História e Geografia. Brasília: MEC/SEF, 1997

CALLAI, Helena C. Aprendendo a ler o mundo: a geografia nos anos iniciais do ensino fundamental. Caderno CEDES, Campinas, n. 66, 2005.

CAStRogiovani, Antonio Carlos (Org.) Ensino de geografia: práticas e textualizações no cotidiano. Porto Alegre: Mediação, 2000.

DEMO, Pedro. Desafios modernos da educação. Petrópolis: Vozes, 1993.

FERREIR0, Emília. Sobre a necessária coordenação entre semelhanças e diferenças. In: CASTORINA, José Antonio: FERREIRO, Emília; LERNER, Delia; OLIVEIRA, Marta Kohl. Piaget-Vygotsky: novas contribuições para o debete. São Paulo: Ática, 1995.

FERREIRO, Emília; TEBEROSKY, Ana. Psicogênese da lingua escrita. Porto Alegre: Artes Mádicas, 1985.

FRAGO, Antonio Viñao. Alfabetização na sociedade e na história. Porto Alegre: Artes Médicas, 1993.

HICKMANN, R. I. Ciências sociais no contexto escolar: para além do espaço e do tempo. In: HICKMANN, R. I. (Org.) Estudos Sociais: outros saberes e outros sabores. Porto Alegre: Mediação, 2010. p. 09-19.

KATO, Mary; MOREIRA, Nadja; TARALLO, Fernando. Estudos em alfabetização: retrospectivas nas áreas da psico e da sociolingüística. Campinas: Pontes, 1997.

LERNER, Delia. Ler e escrever na escola: o real, o possível e o necessário. Porto Alegre: Artmed, 2002.

MARTINS, Rosa Elisabete Militz Wypyczynski. O ensino da Geografia em questão: um olhar sobre o ensino médio. Dissertação (Mestrado). Passo Fundo: UPF, 2004.

MELLO, Guiomar Namo de. Educação escolar brasileira: o que trouxemos para o século XXI? Porto Alegre: Artmed, 2004.

SMOLKA, Ana Luiza. B. A criança na fase inicial da escrita: a alfabetização como processo discursivo. 8. ed. São Paulo: Cortez, 1999

STRAFORINI, Rafael. Ensinar geografia: o desafio da totalidade-mundo nas séries iniciais. 2. ed. São Paulo: Annablume, 2004.

VAL, Maria da Graça Costa. O que é ser alfabetizado e letrado? 2004. In: CARVALHO, Maria Angélica Freire de (org.). Práticas de Leitura e Escrita. 1. Ed. Brasília: Ministério da Educação, 2006. 